\title{
Sports Games: for an Understanding Teaching of the Game
}

\section{Fernando Tavares}

\section{Introduction}

$\mathbf{I}_{\mathrm{r}}$ nternationally sports games occupy a prominent place in the set of activities performed by children and youth. To that fact adds the abiding interest of the media in sports events, both locally and internationally. It is therefore a huge responsibility of all of those who have as job the teaching of these sports.

In this regard, and although in recent decades there has been a renewed theoretical and conceptual models of teaching, we still acknowledge that the teaching practice of the game in the sports games focuses almost exclusively on aspects of motor execution of basic skills in no contextualized situations. Thus, it is usual to observe that players exercise these skills during a certain time, after which they pass on to another skill and so forth. The assumption that is inherent to this way of proceeding is to think that performing a certain number of repetitions of this ability will be enough for players to achieve a good level of mastery of them.

However, what is often verified is that when these youngsters go to practice the real game, they cannot apply those skills in the game context. Why? What are the reasons which may contribute so the practitioner cannot reproduce in the competition what he achieves in the training? This observation leads us to question whether this type of process, based on repetitions of technical gestures, to be more appropriate for young players to make the transposition of skills to their performance in the game. The point is that the relational dynamics of the game in sports games, results

Fernando Tavares, Professor in Faculty of Sport - University of Porto, Portugal. from the simultaneous existence of cooperation and opposition. This means that players are faced with constraints and unexpected situations, and therefore need to adapt to these ever-changing situations and that result from that confrontation.

The cognitive and constructivist prospects put back the approaches about sports games in areas more overlooked such as "the realm of the tactics and its complex interaction with the technique, involving the knowledge, understanding, decision making and the capacity of action in a game situation (Bunker \& Thorpe, 1982; Rovegno, 1995; Gréhaigne et al. 2005; Hooper, 2002; Graça \& Mesquita, 2002). Several studies have confirmed this situation and proposing a change in conception, which lends itself more and more attention to the type of learning that the players do. That is, increasingly aiming that the player understands what they learn and not just a simple executor of actions that they do not understand, exercising the so-called "understanding models" a decisive role.

Thus, it is necessary that the players have skills with quality, to enable them in game situations with some complexity, to effectively intervene in the performance thereof. This means that the acquisition of skills in the learning process must take this reality into account, because the higher the level of practice becomes, more demanding is for the player the need to know and to effectively execute their skills. Therefore, it is essential that young players during their training process are subject to a teaching model that allows them to acquire and develop their skills so they can match what is required in the game. 
Currently, we can identify several models of teaching, which leads us to question why this reality, why some are or could be better than others. Does the understanding model is intended to be applied in physical education classes in school, while the technical model is to be applied in the sport of performance? We think that what changes are the circumstances in which it is applied and developed rather than the objectives it proposes itself, so that the teaching model must be the same.

In traditional teaching models of sports games, as the "technical model" it is emphasized the learning of the technical elements, presented and performed in no contextual situations, while little importance is attached to the tactical content. The game is broken into various skills and then the learner has progressed in a model going from simple to complex skills. Dissatisfaction with the technical model, led to the search for alternative approaches. Thus, and according to Graça (2002), "have been developed, tested and disseminated alternative models for the game teaching, putting more emphasis on tactical component" and which can be fit in the so-called "understanding models: (i) The Model of Teaching Games for Understanding (Bunker \& Thorpe, 1982); (ii) Developmental Model (Rink, 1993); The Sport Education Model (Siedentop, 1987), (iv) the Competency Model in Game Invasion (Musch \& Mertens, 1991), (v) Tactical Decision
Learning Model (Gréhaigne \&Godbout, 1995). In the opinion of these authors, the understanding teaching in sports games fosters through reflection on practice, the connection of which is learning from what is known and, in turn, recognizes and promotes the autonomy of the player through constant evaluation of the adequacy of means employed with the objective to be achieved in each practice situation.

In this sense, the Model of Teaching Games for Understanding by Bunker and Thorpe (1982) presents an approach to the game in which the understanding of it has an important place. They propose the following analysis model of the sports games (Figure 1): (1) Game - As the model indicates, learning is game-based so that there is always some form of opposition; (2) Game appreciation - In recognize the purpose of the game time should be given for athletes to see what the game is all about; (3) Tactical awareness - Problem solving is a critical approach to teaching games for understanding. Beginners are introduced to tactics by the gradual introduction of movement principles, based on simple ideas of space and time; (4) Decision Making - What to do, how to do it and when to do it - with increased appreciation of the game and tactical knowledge, players show a much greater understanding of when to pass/shoot/dribble; (5 and 6) Skill Execution and Performance - The model also emphasises skill execution and performance, but only after the players recognizes a need for a particular kind of skill. 


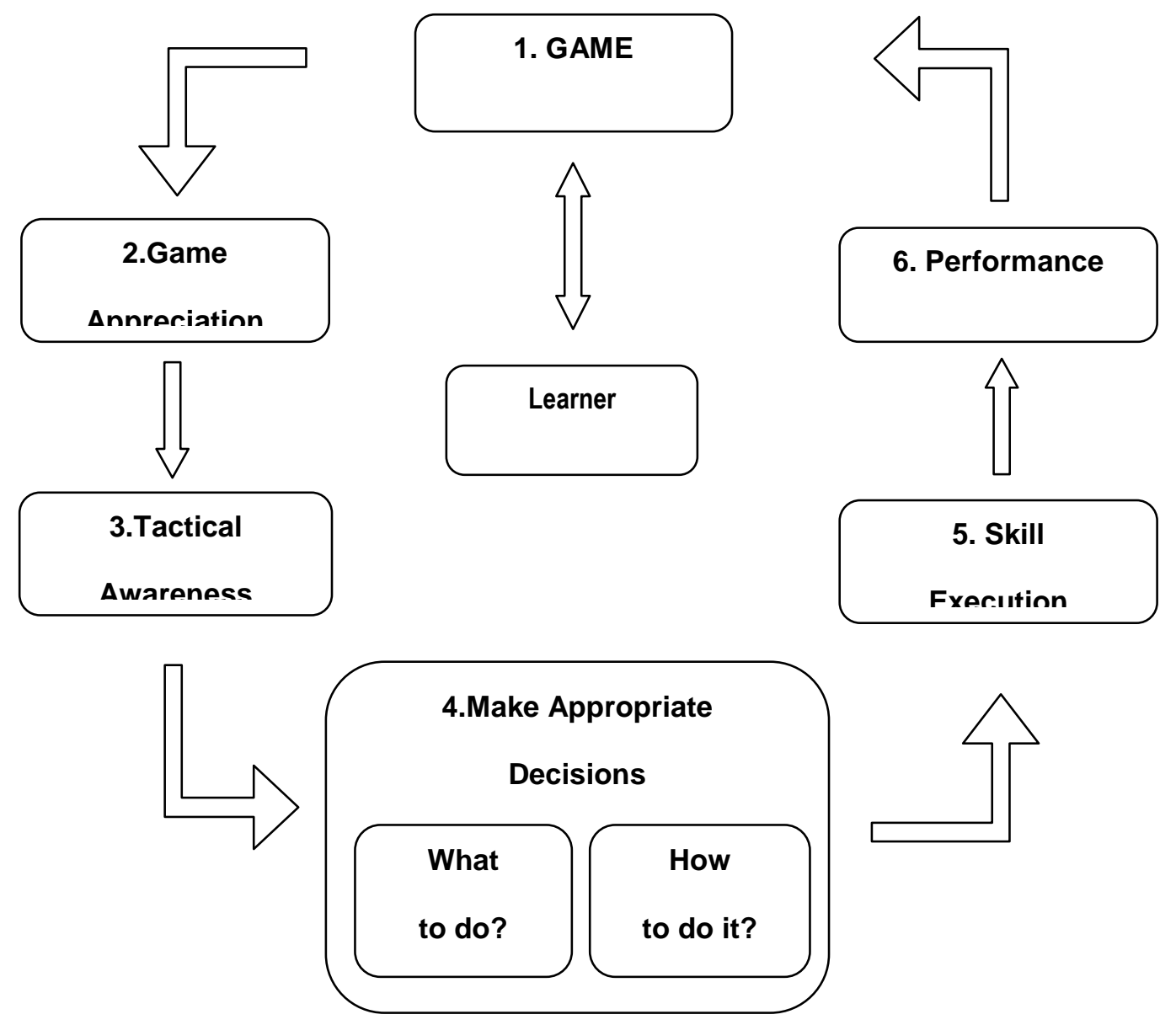

Fig.1 Model of Teaching Games for Understanding by Bunker and Thorpe (1982)

This approach to the understanding of the game, focuses on the conscious tactics and procedures of decision making prior to the selection of motor skills and its performance, suggesting that the players have an initial idea of the sport and what they can expect from them, so as to arouse their awareness tactic to allow them to apply the techniques that are necessary for the game. The model comes as a "reaction to the traditional approach to teaching the game too focused on technical no contextualized" (Graça, 2002), and put questions to the players "what to do" and "where to" and not just "how to". The game context and the meaning of actions, the "whys" have precedence over technique, justifying their opportunity and suitability. Isolated skill development is only utilized when the student recognizes the need for it.

The evidence of the nature of the understanding models leads us to a cognitive involvement in learning and has shown that cognitive assumptions are required sooner than many coaches think, and that knowledge is present from an early age (childhood). Given this reality, we might ask to what extent it is appropriate to delay the tactical and strategic knowledge in the initiation sportive process, giving only emphasis to of the domain of technique. According to Tavares (2005), investigations on the characteristics of expert players and the differences between experts and novices, allow to highlight the cognitive advantage, which highlights the role of knowledge and experience in sport, knowledge that in experts is organized and hierarchical. Thus, it is important to know how to provide this knowledge from the early stage of initiation, so that players can, from the beginning, organize their cognitive-motor features in order to give solution to the problems of the game without having to wait for the domain of techniques. With regard to the knowledge involved in the sports games is a practical knowledge, which requires an understanding of the procedures involved in the game and the contextual acquisition of skills once a technical skill only has meaning in a 
context and is where one must learn and where one acquires full significance.

Given the cognitive demands of learning sports, the understanding model of the sports games teaching seeks to provide the player to go to acknowledge the challenges and generate their own solutions, identifying motor resources that mobilized in his development. In sports games where there is a high degree of variability, that allow players to deduce rules of action based on the evaluation of the relationship between resources that are used in relation to the objective to be achieved at all times. For that it will be as Devis and Peiró (1992) referred, necessary to "teach the contextual aspects and tactical principles of the sports games because they are the ones that form their understanding, the intelligent active involvement and the useful domain of technical skill." It means, it will allow the player to organize their game action in an intentional and adapted way to the contextual characteristics of each sports game, and equally be able to apply these rules of action to other similar situations. We therefore think that in the teaching of sports games we can promote the "know how" from the understanding model, once this is based on recognition of cognitive skills of the player and promotes them to get involved actively in the construction and control of their own learning.

We must understand that must be the practice that players need on each moment and not what adults wish. From the perspective of adults, what can be considered basic to participate, can be too demanding for the player. Accordingly, the presentation, development and refinement of skills in the game, must assume an interest within the possibilities of the player. With a purely technical approach, the player does not know what good is all that is offered to him. This does not mean we should abandon the teaching of technique in sports games, but only questioning their dominant and almost exclusive use in the teaching-learning sports games.

In summary, we corroborate the opinion of several authors who argue that the tactical approach of teaching the game puts the player at the center of teaching-learning process if we are to truly adopt a constructivist progression
(Bunker \& Thorpe, 1982; Gréhaigne \& Godbout, 1995; Rink et al, 1996; Hooper, 2002; Gréhaigne et al, 2005).

\section{The nature of the practice in sports games}

Several studies made in laboratory conditions (Shea \& Morgan, 1979; Meira \& Tani, 2001), under the Motor Learning, grounded in the theory of contextual interference, have demonstrated that the variation of conditions of practice promotes the learning process. In this context, research studies test two types of organization of practice during task acquisition: constant and varied. By constant practice means the practice of the same task always under the same conditions of realization. Varied practice consists in repetition of variations of the same task in which its parameters were relatively changed, providing variations on the same skill. It is often verified better performance of the group with constant practice in the acquisition and levels of higher performance than the group with variable practice on retention and transfer tests. That is, the variability of practice conditions has negative effects on acquisition (temporary effects), but positive in the retention and transfer of learning (permanent or lasting effects). However the characteristics of the motor task or the level of development of the subjects are aspects that seem to interfere with the effects mentioned above.

One of the most important implications of research on the constant practice regards to the impact of movements repetitions in learning skills. The paradox of constant practice is that it produces efficient performance during initial training, but does not create lasting learning. Players get a good performance because they exercise in a stable and predictable environment (which is the opposite in most situations in sports games, where skills are of open nature and low organization) being capable of fine adjusting the parameters of motion of a trial to the next.

Thus, to exercise according to a set of conditions, different tasks better prepare players for dealing with the conditions of a new task than those who practice in immutable conditions (constant). The technical moves should take 
place in situations with changes so the player understands when and where should carry out certain action. This view contradicts another who believes that motor skill of a player is simply related to their ability to perform accurately and consistently a particular movement and without entailing an analysis of involvement conditions in which it takes place. This seems to us a wrong idea because "make a move detached of context without a reading of the involvement, does not characterized a skill whatever consistent it is" (Tani, 2008). Therefore, it has grown the idea that skill in sport is not merely a product of physical prowess of the player (Allard, 1984; Ericsson, 1996; Williams et al, 2004; Tavares, 2005; Tani et al, 2006). It is demonstrated that expert players are typically characterized by having higher perceptual and cognitive skills when compared to novice players (Tavares, 2005, Williams et al, 2004).

In this context it is clear the need to practice and learn all the skills (perceptual, decision-making and execution of movement) of the respective sport while playing the game (as in the approach to teaching skills in the games for understanding). This seems to be a better way to learn than the traditional approach to learning the skill in isolation. Experiences of varied practice, especially during the formative years seem to have been particularly useful in developing aspects of performance in relation to expert players (Abernethy et al, 1998).

Hence there is a set of authors to claim the necessity of learning and acquiring skills be performed in a contextualized way (Graça, 2002; Gréhaigne et al, 2005; Temprado \& Famose, 1999; Tavares, 2005, Tani et al, 2006; Tani, 2008). This means that the player must learn the skills in the presence of colleagues and adversaries to better understand the reason of their movements' application, as well as providing the possibility of other variations of movement resulting from the constraints of situation. Therefore, we must remember the necessity of the technique teaching in sports games to be done in environments that integrate the specificity of the game, since the technology domain requires adaptability. That is, the player can perform well the technical gesture, but unless you know how to apply properly at the time of the game of no avail is the domain of this technique!

\section{Concluding Remarks}

It is difficult to talk about teaching without learning, but the opposite often happens. It is not by chance that it is often used the denomination of teaching-learning process, once the connection between them is crucial. Therefore, we believe that learning and teaching occur at the same time. Since the intent is to approach a teaching that produces significant learning, we must take into account the learning factors that can help us raise a game teaching focused on the knowledge of the player.

In general, the basic motor patterns are relatively easy to improve and refine. On the one hand, maturation, on the other hand the possibility of using them in various contexts, make them the needed motor background for new learning. However, the simple maturation should not be the one that affects the learning and game teaching (because one should not be dependent on the maturation of the young to be taught). Therefore, the acquisition of motor learning that can be applied in sports games is important, as well as skills more or less effective, because these actions put the player in a position of advantage against opponents. The point is that it is necessary that such learning occurs in the context in which it will be applied. Another important aspect to consider in the learning of skills regards the changes adaptability that requires flexible patterns of movement. If learning is entirely guided, eliminating freedom in the choice of responses, the emphasis will be given only to the invariable aspect of ability, contributing to the formation of stereotyped patterns of movement. However, if an excess of freedom is tolerated, it will be difficult to get the consistency needed to achieve the objective with experience. Therefore, Tani et al. (2006) consider that one should provide freedom in the choice of alternatives and encourage players to explore their movement potentialities. In the opinion of those authors, at the beginning of learning, the movements will be inconvenient and confuse. However, resulting from the guidance and 
instruction received and the intrinsic feedback, its macrostructure will become gradually ordered, until a pattern corresponding to a technique will be found.

For the teachers and coaches, the teaching understanding, from the standpoint of learning the skills of the game, seems to pose a difficulty that is not easy to solve. What happens when you put a group of young players a tactical situation that they cannot solve because they have lacked the means (techniques) that help them meet such situation? In this context, the teaching model used is critical and should use the balance in the technique and tactics requirement at every stage of the proceedings. That is, what we want is that the players perform a technique with a high level of demand, so it should provide a simple tactical environment and vice versa.

Finally, this is not a finished once experts continue to debate how best to teach the game and are gaining new insights into how best to integrate technical and tactical aspects of games to enhance player performance and interest. However, it seems clear that we need to fully understand the game for better to play!

\section{References}

ALLARD, F. (1984). Cognition, expert performance and sport. In M. Whiting (Eds.), New paths to sport learning, 22-26. Ontário, Coaching Association of Canada.

ABERNETHY, B.; WANN, J. \& PARKS, S. (1998). Training perceptual-motor skills in sport. In B. Elliott \& J. Mester (Eds.), Training in sport (1-69). Chichester, West Sussex: Jonh Wiley \& Sons.

BUNKER, D.; \& THORPE, R. (1982). A Model for the Teaching of Games in Secondary Schools. Bulletin of Physical Education, 10,916.

DEVIS, J.; PEIRÓ, C. (1992). Nuevas perspectivas curriculares en Educación Física: la salud y los juegos modificados. Barcelona: Inde.
ERICSSON, K.A. (1996). The road to excellence. Mahwah, NJ: Erlbaum

GRAÇA, A. (2002). Concepções didácticas sobre o ensino do jogo. In S. Ibañez-Godoy \& M. Macías-García (Eds.), Novos horizontes para o treino do basquetebol (21-36). Cruz Quebrada: Faculdade de Motricidade Humana, Universidade Técnica de Lisboa.

GRAÇA, A.; MESQUITA, I. (2002). A investigação sobre $\mathrm{o}$ ensino dos jogos desportivos: ensinar e aprender as habilidades básicas do jogo. Revista Portuguesa de Ciências do Desporto, 2 (5), 67-79.

GRÉHAIGNE J-F; GODBOUT, P (1995). Tactical Knowledge in Team Sports from a Constructivist and Cognitivist Perspective. Quest, 47:490-505.

GRÉHAIGNE, J-F; RICHARD, J-F; GRIFFIN, L. (2005). Teaching and learning team sports and games. Routledge.

HOOPER, T. (2002). Teaching games for understanding: The importance of student emphasis over content emphasis. JOPERD, 73(7), 44-48.

MUSCH, E.; MERTENS, B.. (1991). L'enseignement des sports collectifs: une conception elaborée à l'ISEP de l'Université de Gand. Révue de l'Education Physique, 31 (1), 720.

MEIRA， C.M.; TANI， G. (2001). The contextual interference effect in acquisition of dart-throwing skill tested on a transfer test with extended trials. Perceptual and Motor Skills, 92: 910-918.

RINK, J. (1993). Teaching physical education for learning. St. Louis: Mosby.

RINK, J.; FRENCH, K.; TJEERDSMA, B. (1996). Foundations for the Learning and Instruction of Sport Games. Journal of Teaching in Physical Education, 15, 399-447. 
ROVEGNO, I. (1995). Theoretical perspectives on Knowledge and learning and a student teacher's pedagogical content Knowledge of dividing and sequencing subject matter. Journal of Teaching in Physical Education, 14(3), 284304

SHEA, J.B.; \& MORGAN, R.L. ( 1979). Contextual interference effects on the acquisition, retention, and transfer of a motor skill. Journal of Experimental Psychology: Human Learning and Memory, 5: 179-187.

SIEDENTOP, D. (1987). The theory and practice of sport education. In G.Barrette, R. Feingold, C. Rees \& M. Piéron (Eds.), Myths; models and methods in sport pedagogy (79-85). Champaign; IL: Human Kinetics.

TANI, G.; SANTOS, S.; MEIRA JÚNIOR, C. (2006 ). O Ensino da Técnica e a Aquisição de Habilidades Motoras no Desporto. In G. Tani; J. Bento \& R. Petersen (Eds.), Pedagogia do Desporto, 227-240. Rio de Janeiro: Guanabara Koogan.

TANI, G. (2008). Equivalência motora, variabilidade e graus de liberdade: desafios para o ensino de jogos desportivos. In In F. Tavares; A. Graça; J. Garganta; I. Mesquita (Eds), Olhares e Contextos da Performance nos Jogos
Desportivos, 85-92, Faculdade de Desporto Universidade do Porto.

TAVARES, F. (2005). A importância das competências cognitivas no desempenho das habilidades do jogador nos jogos desportivos colectivos. Revista Treino Desportivo (7),especial- 6, ano VIII-3 ${ }^{\text {a }}$ série, 24-31.IDP.

TEMPRADO, J-J; FAMOSE, J.P. (1999). Análisis de la dificultad en el tratamiento de información y descripción de las tareas motrices. In J-P. Famose) (director), Cognicion y Rendimento Motor, 177-195. INDE.

WILLIAMS, A. M; WARD, P.; SMEETON, N.(2004). Perceptual and Cognitive Expertise in Sport: Implications for Skill Acquisition and Performance Enchancement. In M. Williams \& N. Hodges (Eds.), Skill Acquisition in Sport Research, Theory and Practice 328-347. Routledge. 